\title{
El hígado y el alma apetitiva en el Timeo de Platón y su relación con la tiranía*
}

\author{
Liver and appetitive soul in Plato's Timaeus and its relationship \\ with tyranny
}

HENAR LANZA GONZÁLEZ**

\begin{abstract}
Resumen: Analizaremos el papel hígado en el Timeo de Platón, su función en el cuerpo y su relación con el alma apetitiva y la de ambos con el hombre tirano y la tiranía tal y como son caracterizados en la República, el Timeo y las Leyes, para explorar la conexión que hay entre fisiología, psicología y política en la visión teleológica del mundo ordenado por el demiurgo.

Palabras clave: hígado, alma, irracional, apetitiva, concupiscible, tiranía.
\end{abstract}

\begin{abstract}
We will analyze the role of liver in Plato's Timaeus, its function in the body and its relationship with the appetitive soul and the relationship of both with the tyrant and the tyranny -as they are characterized in Republic, Timaeus and Laws- to explore the connection between Physiology, Psychology and Politics in the teleological vision of the world ordered by the demiurge.
\end{abstract}

Keywords: liver, irrational, appetitive, concupiscible, soul, tyranny.

\section{Introducción}

El interés que despertó el hígado en la Antigüedad está atestiguado por textos médicos, filosóficos y literarios, así como por reproducciones escultóricas de distintas civilizaciones, como la babilónica, la griega, la etrusca y la romana.

El hígado es identificado con la sede de las pasiones en textos de los más diversos géneros. Por ejemplo, en la Ilíada, Hécuba, reina de Troya, quiere comerse el hígado del asesino de su hijo Héctor, Aquiles: "hombre violento cuyo hígado ojalá pudiera yo comer hincándole los dientes". ${ }^{1}$ En las obras de los tres grandes trágicos, encontramos referencias a

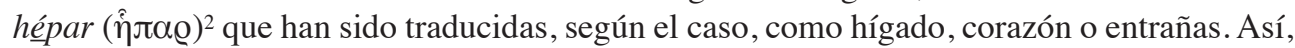

Recibido: 05/02/2017. Aceptado: 20/10/2017.

* Este artículo es producto del proyecto de investigación "Filosofía y Ciencia en los Diálogos de Platón" financiado por la Universidad del Norte.

**Profesora asistente. Departamento de Humanidades y Filosofía. Universidad del Norte. lanzam@ uninorte.edu.com

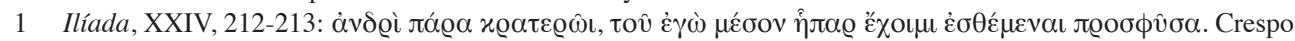
traduce "medio hígado" y Segalá "hígado".

2 Las lenguas romances perdieron el nombre del latín clásico para 'hígado', que es iecur, relacionado con el griego hēpat(o)- y lo sustituyeron por fìcātu $(m)$ que desde el latín tardío era la palabra popular para 'hígado'. Procede de un guiso que se hacía con hígado e higos, de ahí su etimología. Su acentuación anómala probable- 
en Esquilo leemos que: "el mordisco de la pena no llega a tocar su corazón"; 3 en Sófocles: "llega a tus entrañas una auténtica aflicción”; 4 y en Eurípides: "¡Oh infelices madres de infelices jefes, cómo me trastorna el hígado el pálido temor!". En los tres casos el hígado está asociado a pasiones tristes: pena, aflicción e infelicidad.

Como sede de la irracionalidad, el hígado es la víscera elegida por los dioses para comunicarse con los hombres, pues, "de las diferentes vísceras de la víctima, es el hígado el que proporciona las señales más claras y las más importantes”. (Bloch, 1985, 46). Así lo evidencia el papel central que juega en la manía, los sacrificios y los castigos. Y debido a la creencia según la cual refleja el macrocosmos -pues todos formamos parte de una y la misma phýsis-, el hígado adquiere un papel central en las prácticas adivinatorias.

En las maldiciones eróticas griegas el hígado es mencionado como un órgano instrumental en el control del deseo, idea que encontraremos posteriormente en la cultura romana, concretamente en Horacio, quien narra que la bruja Canidia enterró hasta la barbilla a un niño y cada día le ponía ante los ojos varias comidas distintas para que, mientras moría de hambre con la vista fija en las viandas, el deseo se le fuera filtrando en el hígado, víscera que, una vez extirpada, sería el ingrediente principal de un filtro de amor (amoris poculum) con el fin de seducir al viejo Varo (Épodo V, 29-40).

Estas significativas muestras extraídas de textos épicos, trágicos y líricos atestiguan el interés que desde diversos géneros y siglos se le ha prestado al hígado y ayudan a introducir y contextualizar el objeto de nuestro estudio.

\section{La teleología platónica y la fisiología médica de Alcmeón de Crotona}

Cuando alguien lee por vez primera la República y llega al libro VII, donde Platón expone el plan de estudios que propone para los guardianes y futuros gobernantes, suele ocurrir que entiende la importancia de la aritmética y de la geometría, incluso de la astronomía y la armonía, pero no la de la estereometría, "el estudio de cuanto participa de la profundidad" ( $R$. VII, 528b), es decir, de todo cuanto es tridimensional. Este es uno de los ejemplos que evidencian cómo la lectura de la República puede iluminarse con el Timeo, a pesar de la oscuridad que Cicerón atribuyó a su contenido (De Fin., II 15). El Timeo, peri phýseos, indaga en las condiciones de posibilidad materiales, sensibles o físicas de la República ideal. Y dado que todo lo material tiene tres dimensiones, la ciencia que debe estudiarlo es la estereometría. Por eso es en el Timeo donde se presentan los cinco poliedros regulares o sólidos platónicos, porque son las figuras estereométricas por excelencia; y por eso es en la parte final del Timeo donde se explora no solo el alma del ser humano, objeto de la psicología, sino también el cuerpo, materia de la fisiología. En el Timeo es,

mente se deba a la tendencia de acentuar como esdrújulos términos cultos. De ficus en latín proceden hígado en español, foie en francés, fegato en italiano, fígado en portugués, fegado en gallego, ficat en rumano, fetge en catalán y occitano, figá en veneciano y figáu en sardo. Cortés, 2011. URL: <http://dicciomed.eusal.es/palabra/ higado $>$

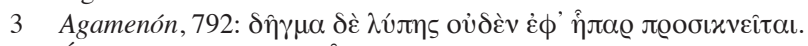

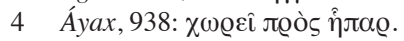

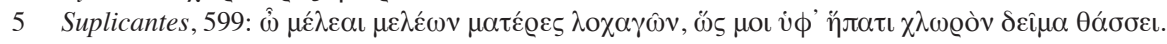


en definitiva, donde se ve con mayor claridad la alineación armónica que tiene que darse entre el microcosmos que es el hombre, la pólis y el mundo; con otras palabras, entre lo antropológico, lo político y lo cósmico, debido a la convicción platónica de que existe una finalidad determinada por la causa inteligente.

El Timeo, además de una obra filosófica, es un documento clave para el conocimiento del desarrollo científico que se había alcanzado en el siglo IV a. C., no solo en lo relativo a la matemática, sino también al arte médica, la téchne iatriké. Esto es así no porque el Timeo sea un tratado científico, sino porque Platón se sirvió de las ideas que estaban en el debate médico de su época (como sabemos por el Corpus hippocraticum o el Anónimo Londinense) y puso ciertos conocimientos científicos al servicio de una visión teleológica del hombre y del cosmos. De hecho, la originalidad platónica consiste en integrar esas corrientes fisiológicas en un marco nuevo: la previsión ( Cuenca, 2011, 260).

Son varios los estudiosos del platonismo que han propuesto que lo que hace Platón en el Timeo es sintetizar dos corrientes anatómico-fisiológicas de la medicina griega: la encefalocéntrica, representada por Alcmeón de Crotona y tratados médicos como Sobre la enfermedad sagrada, y la cardiocéntrica, asociada a Empédocles y al tratado médico Sobre el corazón (Manuli-Vegetti, 2009, 99). Hay quien afirma que Platón recoge, unifica y modifica estas teorías para explicar la creación del cuerpo humano y algunos de sus problemas físicos y psíquicos (Nutton, 2004, 118). Otros consideran que la lectura finalista según la que Platón describe los órganos y las funciones ensancha el marco de lectura del Timeo desde la fisiología a la metafísica, la teología, la psicología, la escatología y la política (Steel, 2001, 118). En opinión de otros, finalmente, hay una conexión entre las teorías de Alcmeón y Platón en lo relativo a la inmortalidad del alma (Fedro, 245c y Leyes, 895e) y de las estrellas en virtud de su movimiento continuo, circular y eterno; en este sentido, Alcmeón habría inspirado a Platón de cara a relacionar el alma del hombre y el alma del mundo, psicología y cosmología (Skemp, 1962, 43). Que Alcmeón defendió la inmortalidad del alma y la conexión entre esta y el movimiento lo sabemos gracias al testimonio de Diógenes Laercio, VIII. 83.

Alcmeón de Crotona fue un médico, fisiólogo y filósofo natural del siglo V a. C. ${ }^{6}$ Que Crotona, una ciudad costera del Sur de Italia, diera origen en el siglo V a. C. a una escuela médica como la de Alcmaeon, Democedes o Kalifón, pudo deberse a la combinación de, uno, su situación geográfica de puerto comercial del Mediterráneo alejado del peligro que en ese entonces representaba el Imperio Persa, y dos, su alto grado de libertad política y nivel moral. ${ }^{7}$

6 Sobre la polémica en torno a la datación de Alcmeón, ver Guthrie, W. K. C. (1999), Historia de la filosofía griega I, Gredos, Madrid, pp. 323-324 y 338-339, que recoge las propuestas de Brandis, Deichgräber, Edelstein, Heidel, Jaeger, Lloyd, Ross, Skemp, Stella, Wachtler, Wellman y Zeller. La postura del propio Guthrie es la siguiente: "es más razonable creer que Alcmeón, como se nos dice, viviera ya en los últimos años de la vida de Pitágoras y fuera un pensador de capacidad e influjo considerables, que no retrasar su vida a la madurez de Platón, con la finalidad de mostrar (con exiguas pruebas) que carecía, en absoluto, de originalidad"(339).

7 Sobre la fama de los médicos de Crotona, ver Herodoto, III, 125 y 129-137. La nota 674 a III 131.2 recoge el dicho "ser más sano que un crotoniata". 
Nuestro conocimiento de la obra de Alcmeón procede principalmente de las siguientes fuentes: el Corpus Hippocraticum (s. V-IV a.C.), Platón (s. V-IV a.C.), Aristóteles (s. IV a.C.), Teofrasto (s. IV-III a.C.) y Calcidio (s. IV).

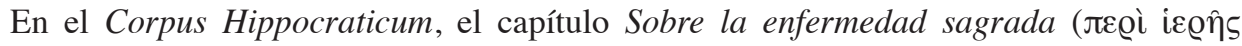
voúrov), también conocida como morbus sacrum o epilepsia, escrito seguramente por un discípulo de Alcmeón, se recoge que "el cerebro es el medio por el cual aprendemos" (Hip., Morb. sacr., 14, VI 387 L).

En el Fedón, 96b, Platón hace recordar a Sócrates su interés juvenil por las investigaciones sobre la naturaleza, cuando se preguntaba si era "el cerebro el que nos da las sensaciones del oír, del ver y del olor de las cuales se genera la memoria y la opinión”. Al comienzo del XII y último libro de las Leyes, el Ateniense, refiriéndose a las infracciones contra el poder militar y estatal, identifica la cabeza como el órgano más apto para mandar al cuerpo "porque por naturaleza tiene todas las percepciones principales" ( Lg. 942e-943a). Y más adelante, en la presentación de la doble función de salvación y conservación adjudicada a la junta nocturna, vuelve sobre la misma idea: "en el alma se encuentra... el intelecto; en la cabeza... la vista y el oído" ( $L g .961 \mathrm{~d})$; y ya al final "cuando en una imagen mezclamos la unión de la cabeza y el intelecto" ( $L g .969$ b).

Aristóteles cita a Alcmeón en Metafísica, A 5 986a27, en relación con los pitagóricos; en Reproducción de los animales, 752b25, y en Historia de los animales, A 11 492a13, para contradecirlo, en el primer caso respecto a las aves y en el segundo respecto a las cabras; y en Acerca del alma, A 2, 405a29, nos informa de que para Alcmeón el alma es inmortal y está siempre en movimiento.

Teofrasto afirma en De sensu, 25-26, que para Alcmeón "el pensar es distinto del sentir" y que "todos los sentidos se relacionan en alguna medida con el cerebro".

Aecio sostiene que "Alcmeón dice que el principio directivo está en el cerebro" (IV, 17, 1-0.407).

Y, finalmente, gracias al Comentario al Timeo de Calcidio, sabemos que Alcmeón fue "el primero que se aventuró a efectuar disecciones" (DK A 10), algo que encaja con lo que se dice en Sobre la enfermedad sagrada en relación a la epilepsia: "si se abre la cabeza se encontrará... con esto se aprende que no es un Dios sino una enfermedad la que injuria el organismo" (Hip., Morb. sacr., cap. 11). Y es Calcidio quien nos advierte:

para conocer en profundidad el pensamiento de Platón es necesario recurrir a la antigua concepción de los médicos y de los físicos, varones ciertamente ilustres que para comprender la sabiduría de la naturaleza pura, investigaron el cuerpo humano, disecando sus miembros y pensando que por último estarían más seguros de sus ideas y opiniones si la razón concordase con la visión como la visión con la razón.

A lo largo del último medio siglo han sido varios los autores que han defendido la originalidad de Alcmeón. En este sentido, un especialista en historia de la medicina antigua como Laín Entralgo afirma que: "Es muy probable, sí, que Alcmeón de Crotona practicase la disección anatómica de cadáveres de animales (anatomía del ojo) y la vivisección (función de centros nerviosos)" (1978, 72) y que, según Alcmeón: 
El cerebro es el centro de la vida del hombre, tanto de la sensorial como de la psíquica. Alcmeón ha sido el primero en afirmar esta importantísima verdad, rompiendo con la doctrina arcaica, según la cual ese centro sería el phren $(1978,83)$.

Otros autores destacan de Alcmeón que "hizo disecciones anatómicas, descubrió la relación entre el cerebro y los sentidos" (Cuervo, 1962, 88); que fue el primero en establecer que hay una comunicación entre el cerebro y nuestros órganos de los sentidos gracias a "los principales nervios sensibles" (Schrödinger, 1997, pp. 73-74), fue "el primero que se planteó en la Grecia antigua, que el órgano principal de nuestro cuerpo era el cerebro" (Gago, 2006, 411) y el primero en dictaminar que "las funciones psíquicas residen en el cerebro" (Outes \& Orlando, 2008, 36).

Sin embargo, hay otros autores que van más allá aún y además de defender el carácter novedoso de los hallazgos de Alcmeón, defienden también la influencia de este en Platón. En su Historia de la Filosofía Griega, Guthrie afirma que: "Es difícil de creer que Platón no estuviera profundamente influido por Alcmeón. (...) Alcmeón presenta (...) ideas que posteriormente desarrollará Platón: el alma como automotriz, la analogía del movimiento circular" (1999, pp. 334 y 339). Y en la entrada "Alcmaeon" de la Stanford Encyclopedia of Philosophy (2017) Huffman concluye que:

Alcmaeon's influence was significant in three final ways: 1) His identification of the brain as the seat of human intelligence influenced (...) Plato (Timaeus 44d) (...). 2) His empiricist epistemology may lie behind important passages in Plato (Phaedo 96b) (...). 3) He developed the first argument for the immortality of the soul, which may have influenced Plato's argument in the Phaedrus (245c ff.).

Ante estas conclusiones, parece prudente detenerse a reflexionar sobre si efectivamente se dio una transmisión de Alcmeón a Platón, bien de forma directa, bien a través de los tratados hipocráticos. Sin mencionar expresamente el pensamiento de Alcmeón, los autores del Corpus Hippocraticum van a hacerlo suyo - en lo esencial, al menos - desde los últimos decenios del siglo V a.C., (Laín Entralgo, 1978, 93).

Para ello, recurriremos al detallado y reciente trabajo de análisis, comparación y comentario de textos de J. Jouanna titulado "The theory of sensation, thought and the soul in the hippocratic treatise Regimen: its connections with Empedocles and Plato's Timaeus", incluido en su obra Greek Medicine from Hippocrates to Galen de 2012 (cap. 11, pp. 195227). ${ }^{8}$

El autor del tratado hipocrático Sobre la dieta (según la traducción al español de los Tratados hipocráticos editada por Carlos García Gual en la Biblioteca Clásica Gredos), cuya datación oscila según los autores entre el siglo V y el IV a.C (Jouanna, 214), dedica el primer libro entero (caps. 1-36) a una discusión de antropología porque está convencido de que no es posible estudiar correctamente el régimen sin un primer y profundo conocimiento del hombre en su entorno. Esta es la razón de que el tratado se incluya en el grupo de los tratados hipocráticos filosóficos, los cuales establecen una conexión entre la naturaleza del

8 Agradezco esta sugerencia a uno de los evaluadores anónimos de una versión previa de este artículo. 
hombre y la naturaleza del universo, entre antropología y cosmología. Jouanna cita a Joly, el más reciente editor y destacado comentarista del tratado Sobre la dieta, quien a propósito de dicha obra afirma que es the "clearest and most accurate formula articulating the doctrine of macrocosmos-microcosmos": man was made 'in imitation of the whole' (ch. 10

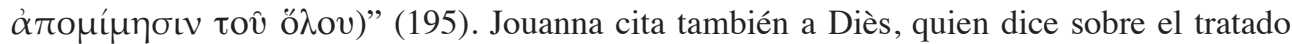
que "all, or nearly all, of the questions it asks are echoed in the history of Greek Philosophy, and particularly in that of the great Socratic schools" (196).

En el capítulo 35 de Sobre la dieta se expone una de las pocas teorías preplatónicas sobre la inteligencia conservadas. Según la contribución del autor del tratado al debate sobre la localización de la inteligencia, esta radica en la psyché, en el alma, la cual está compuesta, como todo ser vivo, de agua y fuego. El autor del tratado propone una estructura piramidal de siete niveles que varían en función del balance o desbalance entre agua y fuego. Bajo el vértice de esa inteligencia máxima (1), el autor despliega los seis desarrollos restantes en función del grado de predominancia del agua (3) y del fuego (3). Encontramos aquí ya que la divinidad como causa de la enfermedad ha sido desplazada por la ruptura de un equilibrio, una simetría. El autor del tratado sostiene que las fallas en la inteligencia pueden ser mejoradas mediante una dieta adecuada que devuelva el equilibrio al binomio fuego-agua. $\mathrm{O}$, lo que es lo mismo, que la naturaleza puede ser mejorada mediante la alimentación, la bebida y el ejercicio, tal y como sostendrá posteriormente Platón en la República cuando se refiera a la educación de los guardianes y en Timeo, 88b-c, 89a y 89c en el tratamiento de las enfermedades del alma.

Jouanna defiende que es posible sostener una interpretación de varios pasajes de Sobre la dieta, especialmente en el cap. 25, según los cuales su autor tiene una concepción dinámica del alma y con movimiento circular, y su velocidad es ideal, ni muy rápida ni muy lenta, evitando la locura y la idiocia respectivamente, cuando se da el equilibrio mencionado entre el agua y el fuego. Es decir, el autor establece una relación entre la velocidad de rotación del alma y la de la inteligencia.

Tras establecer los paralelismos entre Sobre la dieta y los fragmentos de Empédocles, Jouanna hace lo propio entre los capítulos 19, 25, 35 y 93 del tratado hipocrático y el Timeo de Platón (2012, pp. 220-227), específicamente con los siguientes pasajes: 34a, 36c, 42c, 43d, 44a, 44b-c, 47d y 86e-87a. Jouanna comienza señalando que, al igual que el autor del tratado hipocrático, Platón usa el término períodos ( $\pi \varepsilon @ i ́ o \delta o \varsigma)$ para referirse al movimiento circular del alma inmortal en 43d y periphorá ( $\pi \varepsilon \varrho ı \phi o \varrho \alpha ́)$ para referirse a la rotación del alma en 36c.

Otro punto en común con el hipocrático es que Platón también conecta las rotaciones dentro del cuerpo con ciclos astrales; ambos sostienen ideas similares sobre la correspondencia estructural entre el microcosmos y el macrocosmos.

A pesar de que Jouanna no descarta una influencia directa de Sobre la dieta sobre el Timeo, también admite la posibilidad de que ambas obras beban de la misma fuente, posiblemente pitagórica.

Ambos, el hipocrático y Platón, conectan la inteligencia con las rotaciones del alma en términos de velocidad: aquel determinando que la inteligencia es perfecta cuando la velocidad del alma es perfecta y este estableciendo como perfecto el conocimiento cuando las rotaciones de lo Mismo y lo Otro se dan en su trayectoria y velocidad ideales. Y en Sobre 
la dieta y en el Timeo los disturbios del alma son la causa del desorden mental: cuando el alma es encadenada al cuerpo, sus rotaciones son alteradas, es incapaz de discernir lo Mismo de lo Otro y se muestra insensata. Las dos razones que ofrece Platón para explicar esto son, una, la abundante corriente de nutrientes que entran y salen del cuerpo (43b) -explicación paralela a la de 86e-87a cuando se refiere a la abundancia de flemas-; es decir, ambos autores, el hipocrático y Platón, asocian el exceso de nutrientes con las alteraciones del alma y la inteligencia. La segunda de las razones platónicas para justificar los problemas del alma es la invasión de lo perceptible, de las propiedades externas de los cuerpos, que producen impresiones o afecciones (pathémata) en 43b-c.

A pesar de todos los argumentos expuestos, Jouanna considera que el fragmento fundamental es Timeo, 44a. Y concluye:

I know no other text in pre-Platonic literature that is so close to the Timaeus as that of Regimen, both for its theory of sensation / perception / intelligence tied into rotations of the soul and for the use of alo $\theta \eta \sigma \iota s$, referring to the sensory particles which come from objects and which are enlivened by an autonomous movement towards the subject" (Jouanna, 2012, 225).

Jouanna cierra su artículo subrayando el hecho de que Platón propone que la etimo-

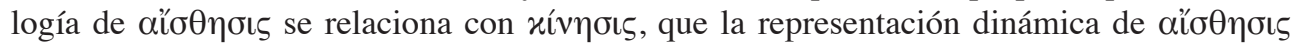
encuentra su soporte etimológico en el Timeo porque Platón conecta el nombre con algo

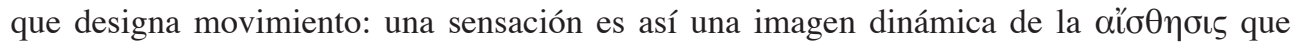
proviene del exterior antes de ser percibida (ver también Crátilo, 431a y el Comentario al Timeo, 3.332, 3-16 de Proclo).

\section{El alma tripartita}

El conocimiento que Platón tuvo de la fisiología de Alcmeón de Crotona se vio reflejado en su concepción tripartita del alma -expuesta en diálogos como la República, el Fedro o el Timeo-, y su tratamiento de la inmortalidad del alma -en Fedro, 245c, Leyes, 895e y, en caso de ser de su autoría, Carta VII, 335. El estado de desarrollo de la ciencia de los siglos V y IV a. C. determinó el desarrollo filosófico de esa misma época, materializándose en una antropología menos dualista y menos extrema que la expuesta hasta diálogos como el Fedón, y más compleja y más consciente de las conexiones del cuerpo y el alma y de la unidad que conforman ambos.

Si bien se suele hablar del alma en relación a su triple función -racional, irascible y apetitiva-, en el Timeo la exposición del alma se estructura en torno a su carácter inmortal o mortal. Inmortal es el alma racional, y mortales son el alma irascible y el alma apetitiva. ${ }^{9} \mathrm{El}$

9 En relación con la mortalidad o inmortalidad del alma, merece la pena destacar la interpretación de Robinson, J. V. (1990), "The tripartite soul in the Timaeus", Phronesis 35 (1), p. 104, quien defiende que "according with the Timaeus, the tripartite soul never perishes", basándose en las palabras del Demiurgo recogidas por Timeo en 41b: "Dioses, hijos de dioses, obras de las que yo soy artífice y padre, que, por mí engendradas, son indisolubles mientras yo lo quiera. Todo lo que está anudado puede ser desatado; no obstante, es propio de un malvado querer deshacer la hermosura de un vínculo armónico, que se encuentra en perfecto estado; por lo cual, si bien toda vez que habéis llegado a la existencia, no sois mortales ni indisolubles en absoluto, no obstante no os 
tratamiento del alma inmortal tiene lugar durante el primer discurso de Timeo, el dedicado a las obras de la inteligencia (Ti., 29d5-47e2), aquello de lo que se ocupa directamente el Demiurgo. Este, tras templar el alma del mundo, crea en el mismo recipiente el alma inmortal de la especie humana (Ti., 41d), que es su parte divina y su guía (Ti., 41c), y la divide en tantas partes como estrellas hay, adjudicando cada alma a una estrella, mostrándoles la naturaleza del universo y las leyes del destino (Ti., 41e), lo cual sintoniza con la afirmación de Alcmeón acerca de la inmortalidad de los astros y del alma, que siempre está en movimiento (DL, VIII, 83). (También en el libro XII de las Leyes se insiste en la necesidad de que los astros tengan alma, $L g .967$ a-b y d).

Todas y cada una de las almas humanas serán sensibles, en primer lugar, a las afecciones violentas, en segundo lugar, al deseo, al placer y al dolor y, en tercer lugar, al miedo y a la ira (Ti., 42); si las dominan, vivirán según la justicia y serán felices, mientras que si son dominadas por ellas, vivirán injustamente (Ti., 42b) e irán descendiendo en la rueda de las reencarnaciones, primero renaciendo como mujeres y después como animales (Ti., 42c), sufrimiento que no cesará hasta que atiendan a la revolución de lo Mismo (trad. de Lisi, Gredos, 1992 y Zamora, Abada, 2010) o de la Identidad y Semejanza (trad., Serrano Cantarín y Díaz de Cerio Díez, CSIC, 2012).

Además de esta, en el Timeo volvemos a encontrar dos menciones al alma inmortal, en 69c, "el principio inmortal del alma" y en 90a-b:

la especie más soberana de alma que reside en nosotros, hay que concebirla de la siguiente manera: ¡es un espíritu divino que el dios ha dado a cada uno!: eso que decimos que vive en el extremo superior de nuestro cuerpo, y que desde la tierra nos eleva en dirección a su connatural, en razón de que somos fruto, no de la tierra, sino del cielo (y con toda la razón lo decimos: pues la divinidad endereza todo nuestro cuerpo suspendiendo cabeza y raíz del lugar en el que se produjo la primera generación del alma). Trad., Serrano y Díaz.

La razón que da el Demiurgo de encargarse únicamente del alma inmortal, divina y racional de los humanos y no de las dos restantes es que "si llegaran a la existencia y de la vida tuvieran parte por mi acción, a dioses serían iguales" (Ti., 41c), lo que permite dejar fuera de la acción demiúrgica el origen del mal (Lisi, 2007, 115). Una vez creada el alma inmortal, la tarea de conformar a los seres humanos es trasladada a manos de los dioses auxiliares o concausas, que serán los responsables de entretejer lo inmortal con lo mortal (Ti., 41c-d). Este hecho, el de vincular cada alma inmortal a un cuerpo mortal sujeto al devenir, traerá consigo una serie de problemas (Ti., 43a4-44c3); no será hasta mucho más adelante, cuando ya estemos escuchando el tercer discurso de Timeo (Ti., 69a4), el relativo a las obras resultado de la mezcla de razón y necesidad o "el uso divino de la causalidad necesaria (alma y cuerpo mortales)" (en traducción de Serrano Cantarín y Díaz de Cerio Díez, 2012, CXCV), que encontraremos el pasaje dedicado específicamente al alma mortal

disolveréis ni tendréis parte en el destino de la muerte, pues habéis obtenido en suerte mi voluntad, un vínculo aún más fuerte y poderoso que aquéllos con los que os ligasteis al llegar a la existencia". 
en su conjunto, su descripción, sus dos especies, su correspondencia con ciertas partes del cuerpo humano y su separación del alma inmortal (Ti., 69c4-72d7).

El alma inmortal y racional se corresponde en el cuerpo con la cabeza, como la acrópolis ( $\dot{\alpha} x \varrho o ́ \pi \circ \lambda ı \varsigma)$ en la ciudad (Ti., 70a6) y está separada del alma mortal por un istmo: el cuello. Del alma mortal se dice que sufre padecimientos tan terribles como necesarios tales como el placer, el dolor, el miedo, la pasión, la esperanza, la sensibilidad irracional o el deseo amoroso (Ti., 69d). El alma irascible también está separada del alma apetitiva por otra barrera, el diafragma ( $\delta \iota \alpha ́ \phi \varrho \alpha \gamma \mu \alpha)$-como las habitaciones de los hombres y las mujeres (Ti., 69e6-70a2), continuando el símil con la pólis (Brisson, 1998, 51) a partir de la repetición

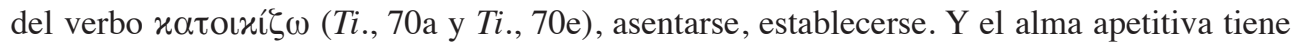
a su vez como límite inferior el ombligo (ỏ $\mu \phi \alpha \lambda$ ó $)$ ).

A diferencia del marcado dualismo antropológico expuesto en diálogos como el Fedón, la concepción tripartita del alma trae consigo una mayor cercanía de la psicología y la fisiología, que es precisamente lo que exploraremos a través del hígado.

\section{El alma apetitiva y el hígado}

La posición relativa del hígado en el Timeo es un primer indicio de su función de bisagra. Timeo divide su discurso en tres partes: las obras llevadas a cabo por la inteligencia (Ti., 27d-47e), las obras llevadas a cabo por la necesidad (Ti., 47e-69b) y las obras llevadas a cabo por ambas, inteligencia y necesidad (Ti., 69b-92c). Y es en esta tercera parte donde aparece el hígado, en el contexto de la creación del alma (Ti., 69c-72e) y el cuerpo del hombre (Ti., 72e-79a). Pero en contra de lo que cabría esperar, esto es, que el hígado estuviera incluido en la descripción de la creación del cuerpo humano, Platón se refiere a él al final del tratamiento del alma (Ti., 71b-72d), justo antes de dedicarse al cuerpo, lo que anticipa su carácter de víscera que conecta la fisiología con la psicología, lo físico con lo espiritual y lo humano con lo divino.

Tras haber asociado el alma irascible con el tórax (Ti., 70a-d), Timeo comienza su exposición sobre el alma apetitiva, "la especie del alma que siente apetito de comidas y bebidas y de todo aquello que es necesario por la naturaleza del cuerpo" (Ti., 70d). (En las Leyes, VI, 782-783a, también se afirma que para los hombres todo depende de tres deseos necesarios: la comida, la bebida y el deseo de procreación). Precisamente por esta función alimenticia, encontramos la siguiente metáfora ( $\mathrm{Ti}$., 70e): lo concupiscible, como fiera salvaje que es, debe estar atado y debe alimentarse en el pesebre, ${ }^{10}$ bien lejos de lo deliberativo, para no perturbar la tranquilidad en la que deben transcurrir las reflexiones de lo racional, principio rector cuyo funcionamiento repercute en el funcionamiento del todo en tanto que se ocupa de lo que conviene al todo y a cada una de las partes. Se observa un paralelismo entre este pasaje del Timeo y las palabras de Sobre la enfermedad sagrada, donde se explica que: "El hombre razona en tanto su cerebro permanezca firme" (Hip. Morb. sacr., 14, IV 387 L), idea confirmada por Teofrasto en Sobre las sensaciones, 26, cuando afirma que dado que todos

10 Esta analogía del pesebre será retomada por Aristóteles en Partes de los animales, II cap. 3, 672b, donde también se insiste en la importancia de separar la zona concupiscible mediante el diafragma, tabique y barrera que protege lo más importante y superior, esto es, el corazón, de lo inferior. 
los sentidos están unidos al cerebro, "al moverse éste y variar su posición, se saturan", así como por Aecio (IV, 17, 1-0.407), quien transmite la idea de que el cerebro es el principio rector (ì $\gamma \varepsilon \mu$ ovixós).

Esta naturaleza salvaje fue la que hizo prever a los dioses auxiliares que ayudan al Demiurgo, las concausas de la causa inteligente, que lo apetitivo no respondería al lenguaje racional (Ti., 71a), ni participaría de la razón y de la inteligencia (Ti., 71d) y su especialidad no sería ocuparse de las palabras, pues lo que verdaderamente arrastra $(\psi v \chi \alpha \gamma \omega \gamma \eta \dot{\gamma} \sigma o \iota \tau o)^{11} \mathrm{a}$ lo concupiscible son las imágenes, más las nocturnas que las diurnas..$^{12}$ De ahí que el hígado sea denso, suave y brillante y tenga las $\delta v v o ́ \mu \varepsilon ı \varsigma$ de la dulzura y la amargura, para reflejar los pensamientos que provienen del intelecto (Ti., 71b). La función de ese reflejo debe ser la de atemorizar al alma apetitiva, amenazándola mediante el medio del que dispone: la amargura, es decir, la bilis, que hace que el hígado se contraiga, se vuelva áspero y cierre sus cavidades, provocando dolores $(T i ., 71 \mathrm{~b}-\mathrm{c})$. Por el contrario, cuando lo que la inteligencia envía son imágenes de tranquilidad (Ti., 71c) el hígado segrega dulzura, lo que provoca un estado de liberación, suavidad, buen ánimo y descanso apacible durante la noche (Ti., 71c), "con el don de la adivinación durante el sueño" (Ti., 71d), tiempo en el que el hombre no participa de la razón.

\section{El alma apetitiva y la tiranía}

A continuación exploraremos la correspondencia del alma apetitiva con la tiranía y el hombre tiránico, tal y como son descritos en la República, el Timeo y las Leyes.

\section{República}

"Para decirlo en términos de la República, la desintegración del estado en el interior del alma del regente venía a sellar la ruina exterior de su poder. Pues el estado, para Platón, no es nunca el simple poder, sino que es siempre la estructura espiritual del hombre que lo representa".

Werner Jaeger, Paideia, 1981, 1043.

Al final del libro VIII de la República Sócrates recurre a una de sus analogías y establece un paralelismo entre el mal que produce la bilis en el cuerpo y el que produce el tirano en la pólis $(R .564 b)$. Un poco más adelante introduce una nueva comparación: debido al gusto que el tirano siente por la sangre y las entrañas humanas descuartizadas, el tirano es como el lobo ( $R$. 565d-566a). En el libro IX, encontramos otro paralelismo entre los deseos que emergen en los sueños y los deseos que caracterizan al tirano $(R$., IX, 571c-d):

11 La elección del verbo $\psi v \chi \alpha \gamma \omega \gamma \varepsilon ́ \omega$ en Timeo, 71a, nos remite a Fedro, 261a7, cuando Sócrates define la retórica como el arte de conducir las almas por medio de las palabras. Ver Taylor, 1928, 510.

12 Ver también Lg. 910a: "el temor que les producen las visiones en vigilia y en los sueños". 
se despiertan durante el sueño, cuando duerme la parte racional, dulce y dominante del alma, y la parte bestial y salvaje, llena de alimentos y de vino, rechaza el sueño, salta y trata de abrirse paso y satisfacer sus instintos (...) en este caso el alma se atreve a todo, como si estuviera liberada y desembarazada de toda vergüenza y prudencia, y no titubea en intentar en su imaginación acostarse con su madre, así como con cualquier otro de los hombres, dioses o fieras, o cometer el crimen que sea, o en no abstenerse de ningún alimento; en una palabra, no carece en absoluto de locura ni de desvergüenza. ${ }^{13}$

El tirano es, según Platón, el peor de los hombres, "el que despierto resulta similar de algún modo al que hemos descrito durmiendo" ( $R$., IX, 576b). Es alguien iracundo y colérico, una bestia polifacética $(R$., IX, 588e), alguien que intenta "gobernar a los otros cuando no se gobierna a sí mismo" $(R ., \mathrm{IX}, 579 \mathrm{c})$.

Si resulta interesante pensar el papel del hígado en conexión con la descripción platónica de los regímenes corruptos, especialmente de la tiranía, es porque el hombre tiránico es aquel cuya organización política interna ( $R$., IX, 591e) está esclavizada por el alma apetitiva, puesto que, como leemos en la República, según son los hombres, así son los estados, y el Timeo es precisamente una exploración de las posibilidades naturales, físicas o sensibles de materialización de esa república. Que Platón vierta al cauce de la reflexión filosófica y política el modelo encefalocéntrico de Alcmeón según el cual hay una relación de mando existente del cerebro hacia el hígado (Hip., Morb. sacr., 6), se traduce en la necesidad de que el alma racional gobierne el alma apetitiva, siendo esta jerarquía y no otra la expresión de la justicia en el ser humano (Lisi, 2007, 114). De aquí que el tirano sea caracterizado como aquel ser en el que dicha relación jerárquica se ha invertido, convirtiéndolo en alguien gobernado por sus deseos, es decir, en una persona incapaz de autogobernarse y, consecuentemente, incapaz de gobernar a los demás. Quien no cuida de sí, difícilmente va a poder cuidar de los otros.

Esta inversión de la cadena de mando en el alma del tirano le impide contemplar la Idea del Bien y, por lo tanto, lo incapacita para ser un buen gobernante. Para que la jerarquía de las tres partes de su alma esté encabezada por su alma racional, debería seguir el proceso de formación que propone Platón en la República y que afecta a lo físico -gimnasia y nutrición, ( $R .403 \mathrm{c}$ y ss)-, a la apreciación estética -música y poesía, $(R .386$ y ss)- y a lo intelectual, aquello que nos permite buscar la verdad $(R .435 \mathrm{e}$ y $436 \mathrm{e})$, razonar $(R .439 \mathrm{~d})$, aprender $(R$. $572)$ y juzgar $(R .582 \mathrm{~d} 7)$-aritmética, geometría, estereonomía, astronomía y armonía $(R$. 522c y ss).

El tema eje de la República -la justicia a nivel individual y político- determina que el análisis esté (...) centrado en cómo es posible reconducir o reducir los aspectos irracionales de nuestra existencia, tanto en nuestra alma como en la sociedad, con el fin de que la justicia pueda realizarse en ambos ámbitos (...) esto lleva a que en varios libros (...) el acento esté

13 La relación del hígado con el deseo y la concupiscencia ha sido plasmada explícitamente por Philip Roth en El lamento de Portnoy: “ «Córrete, Muchachote, córrete ya», aullaba enloquecido el trozo de hígado que — no menos enloquecido, yo - me compré una tarde en una carnicería para luego someterlo a violación tras una valla publicitaria, camino de mis clases de bar mitzvah". Roth, 2007, 16. 
puesto en el conflicto interno del alma y la sociedad, su complejidad y el tipo de procesos internos que contribuyen a exacerbar el conflicto o a paliarlo. ${ }^{14}$

La salud física y la educación del alma, que se autoexamina y domina sus apetitos, consigue que estos no perturben el alma racional y esta pueda percibir todo tal y como es; es decir, busca el reposo de las dos partes inferiores del alma, pues "es en este estado cuando mejor puede alcanzarse la verdad y menos se presentan las visiones prohibidas de los sueños" $(R$. $572 b$ ). Para Platón, los sueños son la prueba de que el alma apetitiva o concupiscible, la "especie terrible, salvaje y sacrílega de apetitos" (R. 572b), está presente en todo individuo,

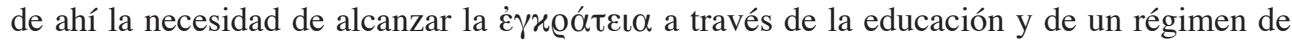
austeridad frente a los deseos de comida, bebida y sexo. "Recordando la semejanza entre el Estado y el hombre" $(R .577 \mathrm{c})$, la relación entre el alma del tirano y la tiranía política es bidireccional: el hombre tiránico será el que "cuente en su alma con el más grande y exacerbado tirano" (R. 575c-d) y "el hombre tiránico es el reflejo del Estado tiránico" $(R$. $576 \mathrm{c})$. En el mismo sentido, "no hay Estado más desdichado que el tiránico" (R. 576e) y "el alma tiranizada será la que menos hace lo que quiere" $(R .577 \mathrm{e})$, pues constantemente es arrastrada por las pasiones violentas y alejada de ese necesario estado de reposo, sintiéndose siempre ávida e insatisfecha cual avaro. El tirano, en tanto que no se cuida a sí mismo ni cuida a los demás $(R .579 \mathrm{c})$, es el más irracional y el más desdichado (R.580a-c) de todos, el más encadenado por los placeres del cuerpo y el más incapaz de gozar de los del alma: la razón, la verdad, el orden y la ley $(R .587 \mathrm{a}-\mathrm{c})$.

Como cierre de este epígrafe merece la pena señalar que casi al final del libro IX $(R$.,

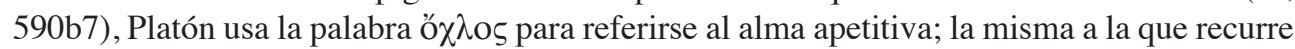

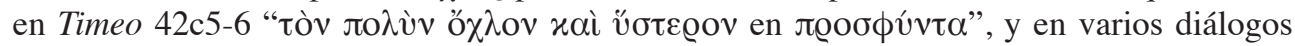
(Gorg. 459a4; Symp. 174a7; Pol. 291a3, 304d1; Phil. 62c5; Lg., II, 670b8, III 700c7, IV 722b7, V 734b6, VII 817c5) para referirse al populacho, que, desde un punto de vista político, está asociado al predominio alma concupiscible (Lisi, 2007, 114).

\section{Timeo}

Si, como asegura Platón al final del Timeo, "las enfermedades del alma son consecuencia del estado del cuerpo" (Ti., 86b), y el alma del tirano está enferma por estar gobernada por el alma apetitiva, en lugar de por la racional, sería plausible pensar que el tirano sufre algún tipo de enfermedad hepática, alguna alteración de la bilis. La explicación platónica es que el goce excesivo impide al hombre percibir correctamente y lo conduce a la locura, "absolutamente incapaz de participar de la razón en ese momento" (Ti., 86b-c). De ahí que Timeo asevere que "el malo se hace tal por un mal estado del cuerpo o una educación inadecuada" (Ti., 86d-e), es decir, por la falta de cuidado físico e intelectual. La explicación fisiológica dada en $T i ., 86 \mathrm{e}-87$, es que si

los humores amargos o biliosos vagan por el cuerpo sin encontrar salida al exterior, ruedan de un lado a otro dentro y mezclan el vapor que expiden con la revolución del

14 Fierro, M.A. (2012), "El residuo de lo irracional: reflexiones a propósito de algunos diálogos platónicos, en: A. Lozano-Vásquez (ed.): Platón y la irracionalidad, Bogotá: Universidad Los Andes, pp. 51-80. En cuanto al conflicto psicológico como fuente del mal, ver también Dodds, E. R. (1980): Los griegos y lo irracional, Madrid: Alianza, pp. 95-211, especialmente p. 200. 
alma de modo que dan lugar a múltiples enfermedades (...) al trasladarse a los tres asientos de aquélla. Donde, eventualmente atacada una, multiplica las varias formas de desenfreno y desgana [apetitiva] o las de osadía y cobardía [irascible] y también el olvido y dificultad de aprendizaje [racional].

En otras palabras, si el exceso de bilis o la amargura no es expulsado del cuerpo, enferma el alma, inclinando cada una de sus partes hacia su vicio específico en lugar de hacia la virtud que le es propia.

La descripción platónica del hombre tiránico concuerda, según la antigua teoría de los cuatro humores, con la del carácter fogoso y colérico. Según esto, podría haber una relación entre el exceso de bilis amarilla y la tendencia al carácter tiránico; dicho de otro modo, pareciera que el hígado del tirano sufre alguno de estos males: 1) produce una cantidad de bilis que lo desequilibra, ${ }^{15}$ 2) no recibe del alma racional imágenes temibles que lo amedrenten y lo refrenen, o 3) aunque las imágenes son enviadas, la superficie hepática enferma ya no es suave, lisa y brillante para reflejarlas. Traducido a un lenguaje médico actual, podríamos decir que si el hígado no puede purificar la sangre, la contaminación se extiende por todo el cuerpo, lo que altera el humor y la lucidez mental y produce enfermedades, como la encefalopatía hepática, que trastorna las tareas cognitivas cuando el hígado no puede eliminar las toxinas del torrente sanguíneo, (lo que en el Timeo, 82e-83, se describe como la putrefacción recorriendo el torrente sanguíneo), o la degeneración hepatocerebral, en la que una insuficiencia hepática puede causar el deterioro de las funciones intelectuales.

Vemos entonces cómo la relación entre la inversión de la jerarquía psicológica idónea y la dificultad de ascender en el conocimiento expuesta en la República está presente también en el Timeo: si un cuerpo grande va a acompañado de una inteligencia pequeña "el alma se vuelve estólida, con dificultades de aprendizaje y olvidadiza" (Ti., 88b). De ahí la necesidad de equilibrar cuerpo y alma: que los matemáticos hagan gimnasia y los gimnastas se ejerciten en música y filosofía ( $T i ., 88 \mathrm{c}$ ) para ser buenos y bellos e imitar al universo (Ti., 88d). Pues quien se cuida a sí mismo y cuida a los demás, es quien vive más acorde con la razón $(T i ., 89 \mathrm{~d})$.

Respecto a la relación del Timeo con Alcmeón de Crotona es importante la llamada de atención de Gigon $(1985,168)$ sobre el hecho de que los conceptos que la teoría médica de Alcmeón son usados por la discusión política de la época. Así, la salud es el equilibrio de fuerzas, la isonomía (ioovouí $\alpha$ ), mientras que la enfermedad es el predominio de una sola, la tiranía o la monarquía. En ese sentido Alcmeón compara el cuerpo sano con un estado bien gobernado:

La salud está sostenida por el equilibrio de las potencias (isonomia tôn dynámeôn): lo húmedo y lo seco, lo frío y lo cálido, lo amargo y lo dulce, y las demás. El predominio de una de ellas (monarkhía) es causa de enfermedad.

Aecio v, 30, 1 (DK 24 B 4)

15 Lisi, F. L. (2007): "Individual Soul, World Soul and the Form of the Good in Plato's Republic and Timaeus", Études Platoniciennes, IV, p. 117: "The dynamis of mind acts on the liver through chemical effects in order to influence the condition of the concupiscent soul". 
Leyes

En el libro VIII de las Leyes Platón reduce a dos las causas de todos los males: 1) la insaciabilidad de riqueza, comida, bebida y deseos sexuales, satisfacer la totalidad de los cuales nos convierte en una bestia ( $L g .831 \mathrm{c}-\mathrm{e})$, y 2$)$ los falsos órdenes políticos, es decir, aquellos que bajo la apariencia de regímenes de gobierno enmascaran lo que no es sino el dominio de facciones, que Platón identifica con la democracia, la oligarquía y la tiranía, caracterizados todos ellos porque el gobernante no gobierna, sino que ejerce coacción sobre los gobernados, que no son gobernados voluntariamente $(L g .832 \mathrm{~b}-\mathrm{c})$. (O, como concluye Pericles ante las preguntas de Alcibíades en el diálogo retratado por Jenofonte en sus Recuerdos de Sócrates, I 2 44, no puede ser ley lo que ejerce no la persuasión, sino la fuerza). En definitiva, la causa de todos los males, tanto los que afectan al alma cuanto los que afectan a la ciudad, es el dominio tiránico de la facción apetitiva. Hay, sin embargo, quien ha asociado la tiranía a la degeneración de la voluntad de orden, propia del alma racional, producida por el amor al honor y al poder (Kalkavage, 2000).

En el libro IX de las Leyes, justo al final de los delitos contra el alma y antes de comenzar los delitos contra el cuerpo, el Ateniense propone que la violación, sea de una mujer libre o un menor, debe ser castigada con la pena de muerte $(L g .874 \mathrm{c})$. Lo que merece destacar de esto es que, si bien la legislación ática no contemplaba esta pena para este delito, ${ }^{16}$ Platón, suponemos que por considerarlo el más grave de aquellos a los que nos impulsa el alma concupiscible, pues el violador es el más tiranizado por el deseo sexual, le adjudica la pena más grave.

A continuación, ya dentro de los delitos contra el cuerpo, el Ateniense plantea el caso de alguien que "llega a asumir el gobierno ilimitado y absoluto de una ciudad" ( $L g .875 b)$, y presupone que esta persona no podrá practicar el arte de la política, que se ocupa de lo común por encima de lo privado, porque su naturaleza mortal lo inclinará hacia la irracionalidad, la búsqueda del placer, el camino del exceso y la persecución del interés personal, todo lo cual abocará a la ciudad a la oscuridad y los males.

Algo similar a lo que ocurre con la violación lo encontramos en el libro XI, donde el Ateniense propone que "el que cometa un delito... por incontinencia en los placeres... debe sufrir una pena más grave” ( $L g .934 a)$. Es decir, que Platón intenta amedrentar la poderosa fuerza motriz de lo irracional mediante los castigos más duros, precisamente porque su objetivo es domeñar a una bestia salvaje que solo responde al dolor y al miedo y no a la persuasión racional.

Finalmente, y sin entrar en el debate sobre su autoría, en la Carta VII, 326d, se nos advierte que quienes solo se preocupan por banquetes, bebidas y placeres amorosos, forzosamente desconocerán la injusticia y encabezarán regímenes tiránicos, oligárquicos o democráticos, pero nunca aristocráticos.

Entonces, por la misma razón por la que en Timeo, 70e, se afirma que lo apetitivo tiene que estar lejos de lo deliberativo, para que el razonamiento pueda darse en paz, el hombre apetitivo, concupiscible, salvaje y tiránico debe estar lejos del gobierno, precisamente para lo mismo: para poder alcanzar y mantener la paz.

16 Platón (1999), Leyes, Madrid: Gredos, 170, n. 152 y 153, el traductor, Lisi, citando a Lisias, I, 30 y 32 y a T. J. Saunders (1994), Plato's Penal Code, 246 y 248. 
Como cierre de este apartado, retomemos lo que se dice al final del Timeo sobre la relación entre los vicios y las enfermedades. En Timeo, $86 \mathrm{c}$-e se hace referencia a los problemas de salud que genera un exceso de esperma, lo que eleva el deseo y, consecuentemente, la posibilidad tanto de placer como de sufrimiento, vidas estas del más gozón y del más desquiciado, respectivamente. De este tipo de hombres dice Platón por boca de Timeo que "su alma está enferma y se halla sin uso de razón por la acción de su cuerpo” (Ti., 86d), razón por la cual no se debe tratarlos como si fueran malos voluntariamente, sino como hombres que están enfermos porque, continúa, la incontinencia sexual es una enfermedad del alma. Lo interesante de este pasaje final sobre los vicios morales es que para explicarlos, Platón recurre al alma y al cuerpo: se llega a ser malo, no voluntariamente, sino debido a una constitución viciosa del cuerpo y a una vida falta de educación y autocontrol. Es decir, que si bien un problema físico no tiene por qué determinar un problema moral, sí parece que exigirá a quien lo padece una mayor capacidad de autocontrol. Y, viceversa: una constitución física sana facilita, o al menos no dificulta, la virtud moral del autodominio, pero tampoco la garantiza; más bien dependerá de la educación que la conciencia de dicha perfección no se traduzca en altivez, orgullo, arrogancia, vanidad o soberbia.

\section{Conclusiones}

Con el fin de iluminar la cuestión sobre la influencia de Alcmeón en Platón, hemos leído conjuntamente las fuentes gracias a las cuales tenemos conocimiento de la obra del primero para, posteriormente, rastrear su presencia en la obra del segundo, lo que ha revelado una común concepción del alma como automoviente y eterna. Si bien en diálogos como el Fedón la antropología platónica es marcadamente dualista, gracias al desarrollo de la concepción tripartita del alma presente en diálogos de madurez y vejez como República, Timeo y Leyes, esa polaridad se difumina debido a una mayor interconexión de cuerpo y alma, fisiología y psicología, que tienen su punto de encuentro en el hígado, víscera mediadora entre hombres y dioses, entre lo sensible y lo inteligible. Que Platón establezca esa relación entre el hígado y el alma apetitiva muestra su interés por explorar la relación entre lo físico y lo psicológico, lo natural y lo moral. Vemos entonces cómo el desarrollo científico de los siglos V y IV a.C. se ve reflejado en la producción filosófica platónica, que lejos de ser una reflexión desconectada del mundo sensible y sujeto al devenir temporal, está determinada por las cuestiones científicas del momento, tanto las médicas como las matemáticas. En este sentido, al valor filosófico del Timeo hay que sumarle un valor documental.

En el análisis de estos tres diálogos, hemos avanzado en tres pasos partiendo del paralelismo sostenido en la República entre alma y ciudad y, consecuente y necesariamente, entre educación y política, entre formación y ascenso hacia la Idea del Bien; hemos alcanzado en el Timeo la conexión del alma con el cuerpo y el necesario equilibrio entre ambos como medio para alcanzar y mantener la salud de los hombres -muy especialmente de los gobernantes-, susceptible de ser mejorada mediante la alimentación, la bebida, el ejercicio y una buena educación, para finalmente arribar a las Leyes, obra en la que encontramos la confluencia final de la psicología y la política de Platón, quien señala aquí como las dos causas de todos los males el alma apetitiva y los regímenes engañosos (algo que si no de forma explícita, sí está ya latente en la Apología en la crítica que hace Sócrates a los atenienses y a la falta de cimientos de la 
democracia). Esa es la razón por la que el hombre tiránico, esclavo de sus deseos salvajes, no debe ser gobernante: para que la pólis pueda llegar a ser una comunidad de placer y dolor y pueda, al igual que el cosmos modelado por el demiurgo bueno sin envidia ni maldad a imagen de un paradigma inteligible que siempre es y nunca deviene, alcanzar el orden y mantenerlo en forma de convivencia pacífica regida por una legislación justa.

Somos naturaleza y educación, phýsis y paideía, en nosotros está la posibilidad de ser, en expresión de las Leyes, peores o mejores que nosotros mismos. Ser mejor que uno es la inclinación que tiene que favorecer la política. Y si no es mediante el gobierno del filósofo, la sofocracia o aristocracia intelectual y espiritual, tendrá que ser a través del gobierno de las leyes, de la nomocracia. En cualquier caso, el gobierno de lo racional, de la noocracia, de la parte mejor del hombre, nunca de la peor.

Conocernos, cuidarnos, formarnos y cuidar al otro. Autoexamen, salud, educación y política. Sócrates, Alcmeón y Platón preparando el terreno a Aristóteles.

Tabla

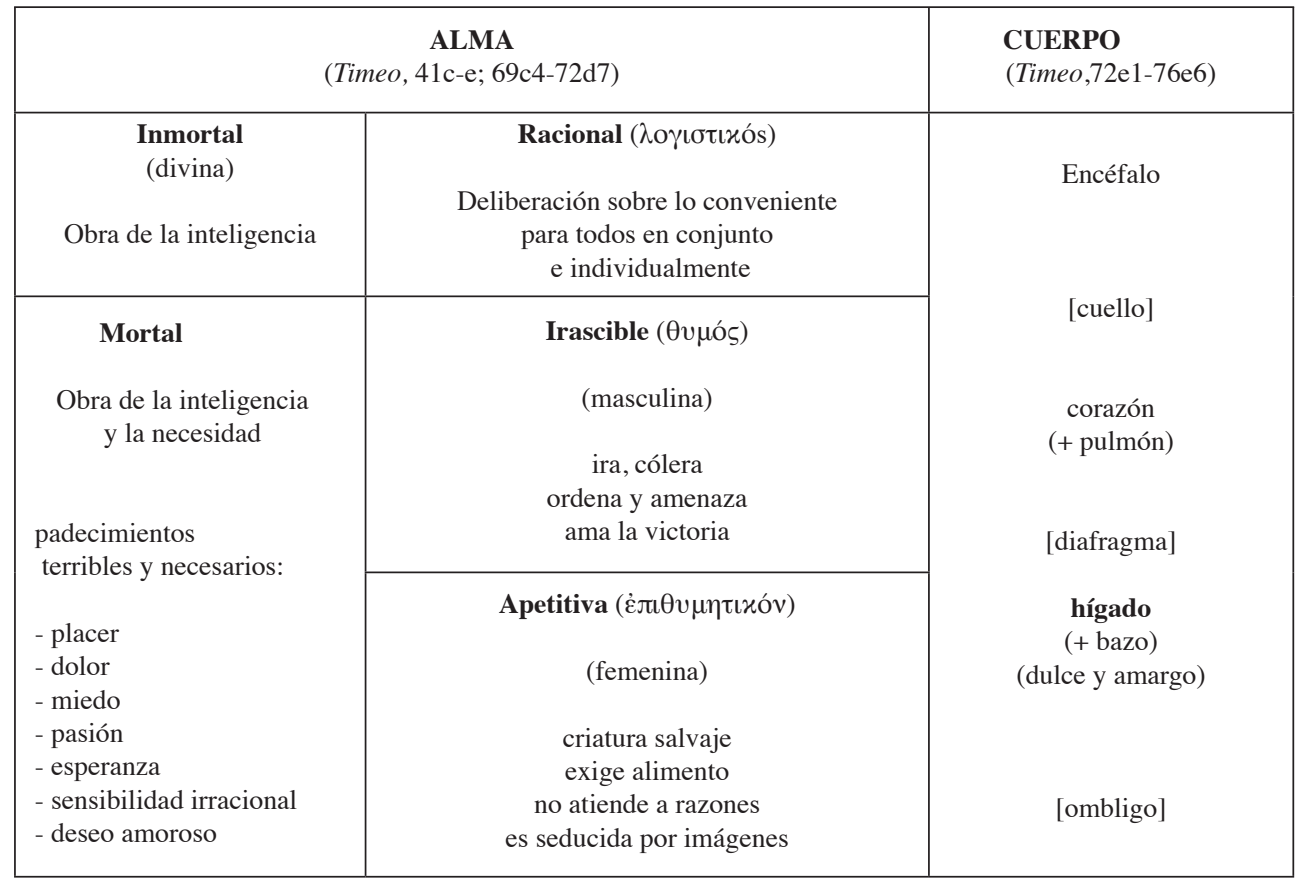

\section{Referencias bibliográficas}

ARISTÓTELES (1983): Acerca del alma (intro., trad., y notas: T. Calvo Martínez), Gredos, Madrid.

ARISTÓTELES (1992): Investigación sobre los animales (intro.: C. García Gual; trad., y notas: J. Pallí Bonet), Gredos, Madrid. 
ARISTÓTELES (1994): Metafísica (intro., trad., y notas: T. Calvo Martínez), Gredos, Madrid.

ARISTÓTELES (1994): Reproducción de los animales (intro., trad., y notas: E. Sánchez), Gredos, Madrid.

BLOCH, R. (1985): La adivinación en la antigüedad (trad. V. M. Suárez Molino), FCE, México.

BRISSON, L. (1998): Le Même et l'Autre dans la structure ontologique du Timée de Platon, Academia Verlag, Sankt Augustin.

CALCIDIO (2014): Traducción y comentario al Timeo (trad. y editor: C. Macías Villalobos), Libros Pórtico, Zaragoza.

CANO CUENCA, J. (2011): Cuando el dios no está ausente. Cosmología y fisiología en el Timeo de Platón. Tesis para la obtención del título de Doctor en Filosofía, Universidad Carlos III de Madrid, España. Disponible en:

<http://hdl.handle.net/10016/13320 >

CICERÓN (2002): Del supremo bien y el supremo mal (trad. V. J. Herrero-Llorente), Gredos, Madrid.

CORTÉS, F. (coord.) (2011): Dicciomed.eusal.es. Diccionario médico-biológico, histórico y etimológico. Recuperado de: http://dicciomed.eusal.es/palabra/higado

CUERVO ESCOBAR, J. E. (1962): Alcmeón de Crotona. Ideas y valores, vol 4, $n^{\circ}$ 14-15, pp. 77-89. Bogotá.

DIÓGENES LAERCIO (2010): Vidas y opiniones de los filósofos ilustres (trad. C. García Gual), Alianza, Madrid.

DODDS, E. R. (1980): Los griegos y lo irracional (trad. M. Araujo), Madrid, Alianza.

ESQUILO (2000): Tragedias (trad. B. Pérez Morales), Gredos, Madrid.

EURÍPIDES (1995): Tragedias completas II (trad. J. L. Calvo Martínez), Gredos, Madrid.

FIERRO, M. A. (2012): El residuo de lo irracional: reflexiones a propósito de algunos diálogos platónicos. In A. Lozano-Vásquez (ed.), Platón y la irracionalidad, Universidad Los Andes, Bogotá, pp. 51-80.

GAGO, L. G. (2006): Alcmeón de Crotona y el problema mente-cerebro. Helmántica, pp. 387-417. Universidad Pontificia de Salamanca, Salamanca.

GIGON, O. (1985): Los orígenes de la filosofía griega. De Hesíodo a Parménides (trad.: M. Carrión Gútiez), Gredos, Madrid.

GUTHRIE, W. K. C. (1999): Historia de la filosofía griega I. Los primeros presocráticos y los pitagóricos (trad., A. Medina González), Gredos, Madrid.

HERODOTO (1979): Historia. III-IV (trad., y notas: C. Schrader), Gredos, Madrid.

HIPÓCRATES (1982): Tratados, Gredos, Madrid.

HOMERO (1991): Ilíada (trad., prólogo y notas, E. Crespo Güemes), Gredos, Madrid.

HOMERO (2006): Ilíada (trad., L. Segalá y Estalella), Espasa, Madrid.

HORACIO (2007): Odas. Canto secular. Épodos (trad. J. L. Moralejo), Gredos, Madrid.

HUFFMAN, C. (2017 Spring): "Alcmaeon", The Stanford Encyclopedia of Philosophy, Edward N. Zalta (ed.), <https://plato.stanford .edu/archives/spr2017/entries/alcmaeon/>.

JAEGER, W. (1981): Paideia: los ideales de la cultura griega (trad.: J. Xirau y W. Roces), FCE, Madrid. 
JENOFONTE (2009): Apología. Banquete. Recuerdos de Sócrates (trad., e intro J. A. Caballero López), Alianza, Madrid.

JOUANNA, J. (2012): Greek Medicine from Hippocrates to Galen. Selected Papers, vol. 40. Brill, Leiden - Boston.

KAlKaVAGE, P. (2000): Plato's Timaeus and the Will to Order. Recuperado de The Imaginative Conservative: http://www.theimaginativeconservative.org/2012/07/platostimaeus-and-will-to-order.html

KIRK, G. S. RAVEN, J.E., SCHOFIELD, M. (1990), Los filósofos presocráticos. Historia crítica con selección de textos (trad., J. García Fernández), Gredos, Madrid.

LAÍN ENTRALGO, P. (1978). Historia universal de la medicina, Salvat, Barcelona.

LIDDELL, HG., SCOTT, R. \& JONES, H., (Eds.) (1996): A Greek - English Lexicon, Clarendon Press, Oxford.

LISI, F. L. (2007): Individual Soul, World Soul and the Form of the God in Plato's Republic and Timaeus. In Études Platoniciennes, IV, pp. 105-118.

MANULI, P. y VEGETTI, M. (2009): Cuore, sangue e cervello. Biologia e antropologia nel pensiero antico, Editrice Petite plaisance, Milano.

NUTTON, V. (2004): Ancient medicine, Routledge, London.

OUTES, D.L. \& ORLANDO, J.C. (2008): Alcmeón de Crotona. El cerebro y las funciones psíquicas. In Alcmeón 57, año XVII, vol. 15, Nº 1, septiembre, pp. 34-49.

PLATÓN (1992): Fedón. Banquete. Fedro (trad. C. García Gual; M. Martínez Hernández; E. Lledó Íñigo), Gredos, Madrid.

PLATÓN (1992): Filebo. Timeo. Critias (trad. M. Á. Durán y F. L. Lisi), Gredos, Madrid. PLATÓN (1998): República (trad., intro y notas, C. Eggers Lan), Gredos, Madrid.

PLATÓN (1999): Leyes (trad., intro y notas, F. L. Lisi), Gredos, Madrid.

PLATÓN (1999): Timeo (trad. C. Eggers Lan), Colihue, Buenos Aires.

PLATÓN (2003): Timeo (trad. Ó. Velásquez), Univ. Católica de Chile, Santiago de Chile.

PLATÓN (2007): Cartas (trad., intro y notas, F. L. Lisi), Gredos, Madrid.

PLATÓN (2010): Timeo (trad.: J. M. Zamora Calvo. Epílogo y notas: L. Brisson), Abada, Madrid.

PLATÓN (2012): Timeo (trad. R. Serrano Cantarín y M. Díaz de Cerio Díez), CSIC, Madrid. PLATÓN (2014): Carta VII (trad, intro y notas, J. Cano Cuenca), Cátedra, Madrid.

ROBINSON, J. V. (1990): The tripartite soul in the Timaeus. In Phronesis 35 (1) pp. 103 110.

ROTH, P. (2007): El lamento de Portnoy (trad. R. Buenaventura), Seix Barral, Barcelona.

SCHRÖDINGER, E. (1999): La naturaleza y los griegos (trad.: V. Gómez Pin), Tusquets, Barcelona.

SKEMP, J. B. (1942): The theory of motion in Plato's later dialogues, Cambridge Classical Studies, Cambridge.

SÓFOCLES (2002): Tragedias (trad. A. Alamillo Sanz), Gredos, Madrid.

STEEL, C. (2001): The moral purpose of the human body. A reading of Timaeus 69-72. In Phronesis, XLVI/2, pp. 105-128.

TAYLOR, A. E. (1928): A Commentary on Plato's Timaeus, Clarendon Press, Oxford.

TEOFRASTO (1989): Sobre las sensaciones (trad., J. Solana Dueso), Anthropos, Barcelona. 